\title{
EMPREENDEDORISMO E NOVOS NEGÓCIOS: OBTENÇÃO DE APOIO PARA STARTUPS
}

Célio Eugênio Da Silva Júnior ${ }^{1}$ Márcia Freire De Oliveira ${ }^{1}$ Miriam Tiemi Takimura Oliveira ${ }^{1}$ Cristiano Camargo ${ }^{2}$

\footnotetext{
${ }^{1}$ Universidade Federal de Uberlândia
}

${ }^{2}$ Unitelos 


\section{EMPREENDEDORISMO E NOVOS NEGÓCIOS: OBTENÇÃO DE APOIO PARA STARTUPS}

\section{RESUMO}

O presente estudo tem como objetivo identificar como o apoio (financeiro e não financeiro) obtido pelas startups de Uberlândia-MG é empregado na criação e alavancagem dessas organizações. A coleta de dados foi realizada em seis startups por meio de entrevistas semiestruturadas feita com proprietários ou sócios-proprietários das empresas. Os resultados evidenciam a relevância do apoio de familiares, mentorias e a participação em programas de aceleração cujo suporte aos novos empreendimentos contribui para minimizar os riscos mediante a gestão mais assertiva das atividades gerenciais do empreendimento. Por outro lado, os empreendedores enfrentam dificuldade em captar recursos de terceiros na fase inicial dos projetos o que leva à necessidade de maior volume capital próprio, podendo inviabilizar o empreendimento.

Palavras chaves: Empreendedorismo, Startups, Apoio, Dificuldades.

\section{INTRODUÇÃO}

$\mathrm{Na}$ atual sociedade o empreendedorismo está marcado pelo aumento da competitividade e pelo grande desenvolvimento tecnológico, assumindo um papel de destaque por ser capaz de impulsionar a criação de empresas de caráter inovador; surgindo da necessidade que se tem, em implantar novos negócios (MORAES, 2012). Estimuladas pelos processos criativos e de inovação as startups surgiram como uma nova forma de empreender, em um contexto onde todos têm acesso imediato às informações, e o sucesso empresarial está diretamente relacionado às empresas que tem a capacidade de transformar essas informações em novas oportunidades de negócio. Dentre as inúmeras estratégias competitivas, que estão surgindo frente a esse cenário extremamente tecnológico, os modelos de startup ganham espaço. Este tipo de negócio é caracterizado como uma forma criada para gerar novos produtos ou serviços, diante de cenários de extrema incerteza e risco. Startup é o termo utilizado para denominar uma empresa geralmente recém-criada, que nasce a partir de uma ideia inovadora normalmente com base tecnológica, possuindo um modelo de negócio escalável, repetível e que está geralmente em fase inicial de atividade, trabalhando em um cenário de extrema incerteza (RIES, 2012).

Ries (2012) ainda coloca que devido a esse cenário de incerteza, o ciclo de vida das startups é menor comparado aos demais tipos de negócios, assim as startups precisam ser ágeis e estar continuamente preparadas para transformações, principalmente em ambientes tecnológicos e mutáveis. O cenário das startups faz sempre referência ao risco, consequentemente, tem-se que salientar os níveis de mortalidade e sobrevivência destes novos negócios no Brasil. Segundo Arruda e Nogueira (2012), 25\% das startups morrem em até um ano de existência, já 50\% morrem com quatro anos ou menos, enquanto $75 \%$ deixam de existir com treze anos ou menos. Ainda segundo os autores, dados mostram que quando a startup é composta desde o seu início por mais de um sócio, são maiores as chances de descontinuidade. 
Segundo o levantamento da Associação Brasileira de Startups - ABSTARTUPS (2016), foram identificadas 4.151 startups em estágio inicial no país ao final de dezembro de 2015 , o que revela um crescimento de $18,5 \%$ em relação ao primeiro semestre do referido ano. Ao passo que há o crescimento do número de startups no Brasil, a taxa de mortalidade dessas empresas é alta. De acordo com o ABSTARTUPS (2016), a necessidade de recurso disponível para suportar este segmento de empresas é cada vez maior, perante a competitividade do cenário desses empreendimentos. Os conceitos base para criação e manutenção de uma startup são: gastar o menor tempo e dinheiro possível (RIES, 2012).

Segundo Sarmento (2016), entre as dificuldades mais comuns enfrentadas pelas startups estão a falta de conhecimento sobre o mercado de atuação; a falta de identidade da marca; a falta de planejamento; e a falta de controle financeiro. Outra dificuldade enfrentada pelos empreendedores se dá em relação à obtenção de recursos financeiros para financiar os seus projetos, principalmente pela falta de capital próprio para investir no negócio, e a alta taxa de juros que são cobrados pelos bancos, fatores que muitas vezes podem inviabilizar o negócio.

Partindo das dificuldades apontadas pela literatura, o presente estudo visa responder a seguinte questão: como os empreendedores obtêm apoio para a criação de startups e de que forma este apoio é utilizado? Visando responder à tal questão o objetivo da pesquisa é identificar como o apoio (financeiro e não financeiro) obtido pelas startups de Uberlândia-MG é empregado na criação e alavancagem dessas organizações

Destaca-se que a cidade de Uberlândia-MG desenvolveu um ecossistema de empreendedorismo, Uberhub, que envolve empresas, associações, instituições de ensino, órgãos públicos e privados que contribuem para a construção de um ambiente favorável ao desenvolvimento de startups, sendo que a cidade ocupa a sexta posição em números de startups no Brasil (Prefeitura de Uberlândia, 2019).

Este estudo está estruturado da seguinte forma (I) introdução, (II) referencial teórico, onde são discorre-se sobre inovação, startups e formas de apoio as startups, (III) metodologia, (IV) resultados e discussões e, (V) considerações finais.

\section{REFERENCIAL TEÓRICO}

Para Atkinson e Ezell (2012), a inovação tem se tornado o direcionador central da competitividade econômica nacional, e é por este fato, que muitas nações estão empenhadas na corrida para a vantagem da inovação global. Segundo os autores, a inovação é fundamental para a geração de emprego e renda, a melhoria da qualidade de vida e da competitividade das nações. De acordo com Hermanson (2011), as empresas denominadas como startups são exemplos de aplicabilidade no cenário da inovação visando sempre atender a uma necessidade da sociedade. Além disso, a inovação desse modelo de empresa é fruto das relações com universidades e relevantes centros de pesquisas, os quais permitem o desenvolvimento de soluções rápidas, dinâmicas e eficientes em meio ao cenário mercadológico (FERRÃO, 2013).

Segundo Hermanson (2011) empreender por meio de startups caracteriza-se pela criação de riqueza; procura de investimento junto a capitalistas de risco (business angels); criação de estratégias e culturas organizacionais; não obedecimento a regras; atuação no horizonte de curto prazo; e dar passos rápidos (caos controlado). Conforme Ferrão (2013), as startups diferenciamse por serem empresas muito dinâmicas, com um potencial de crescimento acelerado, que muitas vezes resulta da sua ligação a universidades e polos de conhecimento, com utilização e 
aplicação da sua tecnologia e know how no mundo empresarial. Em alguns casos, estas empresas são depois compradas por empresas de maior dimensão, que se beneficiam da invenção tecnológica destas startups.

Contudo Ferrão (2013), ressalta que a possibilidade de uma startup conseguir sobreviver no mercado é pequena, pois uma empresa cuja característica principal é a inovação, a busca por um novo modelo de negócio se torna de extrema relevância. Se a empresa obtiver sucesso, o retorno é alto, porém os riscos são altos, principalmente se não houver aporte financeiro de uma aceleradora ou outro tipo de investimento privado. Lima (2014), destaca que as startups são uma forma de alavancar a inovação, sendo importante a existência de apoio às as iniciativas dessas empresas, o que pode ocorrer por meio de aceleradoras, incubadoras, seed capital, investidores anjo, crowdfunding, venture capital, private equity, capital próprio entre outras fontes.

No que tange ao apoio financeiro às startups considera-se que o sistema financeiro é elemento central nas discussões sobre inovação e, remontam ao trabalho seminal de Schumpeter (1985). Para o autor, a concessão de crédito é a função básica dos capitalistas e é por meio do crédito que o capitalista consegue forçar o sistema econômico para seguir por outros canais. Nesse sentido, o capitalista é aquele que dispõe de capital suficiente para financiar novas combinações empresariais que podem gerar novos ciclos de negócios. Segundo Hall e Lerner (2010), embora o papel do capitalista seja essencial para o financiamento de novos empreendimentos, deve-se levar em conta que alguns aspectos podem comprometer a disponibilidade de investimentos para financiar a atividade inovadora das organizações dentre eles, perspectiva de retornos pequenos sob o investimento, tendo em vista a inabilidade de conseguir lucros oriundos de uma invenção, a incerteza e o risco associados aos projetos e baixo otimismo por parte dos gestores em relação aos projetos.

O conceito de financiamento à inovação leva em consideração as diversas fontes de financiamento de longo prazo que formam a estrutura de capital de uma empresa, como dívidas ou capital próprio (LEMES JR.; RIGO; CHEROBIM, 2010). Assim, existem formas internas, que dizem respeito à realização de reinvestimentos oriundos de lucros retidos e depreciação, e externas, que representam a obtenção de recursos por mecanismos como a emissão de título no mercado de capitais, financiamento bancário, contratos de arrendamento mercantil e financiamento em mercados internacionais (CHEROBIM et al., 2011). De acordo com o Manual de Oslo (OCDE, 2005), as despesas com inovação podem ser financiadas por financiamento próprio; financiamento originário de empresas subsidiárias ou associadas; financiamento de empresas não financeiras; financiamento de empresas financeiras (empréstimos bancários, capitais de risco, etc.); financiamento do governo (empréstimos, subvenções, etc.); financiamento de organizações supranacionais ou internacionais (EU, etc.); outras fontes.

Como é possível observar, a tipologia classificatória apresentada pela OCDE (2005), contempla os elementos internos e externos apresentados por Cherobim et al (2011) que já apresenta os capitais de risco (venture capital, private equity, investidores anjos, etc.) como uma forma de financiar a inovação por meio de empresas financeiras. O venture capital é o nome usado para descrever as classes de investidores de risco. Mesmo assim, em geral, os fundos de venture capital investem em empresas de médio porte, que já tem um faturamento expressivo e que pode ser definido como uma forma independente e focada em investimentos 
de companhias com crescimento rápido (HALL; LERNER, 2010). Ainda segundo os autores a diferença entre os outros tipos de investimento é a conexão e o relacionamento que os financiadores desenvolvem com as empresas que financiam. Dessa forma, fatores como assimetria da informação ou perigo moral, questões frequentes em novas firmas, são diminuídas e o possível comportamento oportunista do empresário financiado é cercado pelo acompanhamento dos financiadores na evolução da empresa.

Para Dornelas (2008, p.167), os principais estágios de investimento de risco em startups, desde sua concepção, são:

- Fase inicial ou da ideia: o capital inicial surge do próprio empreendedor, de amigos;

- Fase inicial (startup): a empresa já está constituída e geralmente tem menos de 1 ano; o produto está sendo melhorado e sua aceitação sendo analisada. Nesta fase, não é muito comum que o capitalista de risco invista na empresa, devido ao alto risco do negócio. Geralmente o seed money (capital semente) é colocado na empresa por angels.

- Fase de expansão: nesta fase a empresa está se desenvolvendo e precisa de mais capital para financiar seu crescimento, geralmente estará com dois a três anos de existência. Esse capital necessário é maior que o seed money e virá da primeira rodada de investimento de capital de risco, o first round. As negociações com o capitalista de risco são muito importantes, pois as cobranças por resultados serão muito grandes.

- Consolidação e saída dos angels e capitalistas de risco: nesta fase a empresa procura uma expansão ainda maior, negocia uma aquisição, parcerias, investimentos com outros fundos, e começa a gerar os resultados almejados pelos investidores iniciais que realizam o lucro, saindo da empresa e deixando o seu financiamento. Começa um novo ciclo na empresa, com a consolidação do negócio e a possibilidade de abrir o capital na bolsa de valores.

O investimento anjo é uma importante fonte de financiamento para empresas jovens que não possuem garantias suficientes para atrair os fundos formais (BURKE, 2015). Segundo Araújo (2017), o investimento anjo no Brasil se efetiva sempre de forma passiva: os empreendedores, através de sua rede de relacionamentos, conseguem apresentar projetos a empresários, executivos ou profissionais liberais bem-sucedidos e estes aportam recursos financeiros e expertise no empreendimento.

Ainda dentre as formas de investimento, existe o seed money (capital semente). Segundo Marinho (2017), há um entendimento de que os investidores anjos são um tipo de seed money, não sendo o seed money apenas denominação de fundos especializados nesta fase de nascimento das empresas. No Brasil, o capital semente também costuma se confundir com o aporte realizado pelas aceleradoras, pois o investimento por investidores individuais ainda está em desenvolvimento, apesar da ascensão de entidades como Anjos do Brasil. Geralmente, os valores não ultrapassam $\mathrm{R} \$ 1$ milhão em troca de até $15 \%$ da empresa. Para o autor, para a obtenção do seed money é necessário que as empresas estejam estruturalmente um pouco mais organizadas, auto gerenciadas e em fase comercial organizada, pois o seed money não agrega valor ao negócio, não havendo a figura de um gestor interessado no dia a dia e sim apenas interessado em relatórios acerca do investimento feito e seu retorno. Eis a justificativa encontrada para que o investimento anjo não seja enquadrado como um seed money, apesar de conseguirem atuar em conjunto.

Uma outra forma de financiamento à inovação mais recente é o Crowdfunding. Segundo Lima (2014), seu surgimento está diretamente ligado à internet, bem como sua forma de 
investir. Nesta modalidade de investimento, várias pessoas de diferentes localizações investem em um projeto ou empresa. Por ser uma forma de financiamentos e investimento muito recente ainda o Crowdfunding encontra-se como uma promissora forma de investir em pequenas e médias empresas que não possuem condições e não são consideradas atrativas para as outras modalidades de investimento. Ao contrário das outras formas de investimentos, o Crowdfunding pode atrair negócios com alto risco e que não apresentam um potencial para atingir lucros excepcionais.

Além das possibilidades anteriores, outra possibilidade é via financiamento de bancos públicos e bancos privados. Lima (2014), afirma que entre os órgãos governamentais os que mais se destacam no aporte, suporte e investimentos a inovações são a Financiadora de Estudos e Projetos (FINEP) e o Banco Nacional de Desenvolvimento (BNDES). Lima (2014), afirma que no Brasil as empresas contam com três fontes distintas de recursos para financiamento: recursos próprios, recursos externos públicos e recursos externos privados. Dessa forma, os recursos públicos e privados são dirigidos para o financiamento de demais atividades e menos para o financiamento direto a $\mathrm{P} \& \mathrm{D}$, pelo fato desse tipo de investimento apresentar um menor risco (LUNA; MOREIRA; GONÇALVES, 2008). À medida que as empresas crescem, elas passam a depender menos dos recursos próprios e conseguem financiamento de outras formas, pois, com o tempo, conseguem desenvolver seus projetos e criar um ativo tangível. No entanto, do período em que uma empresa inovadora é criada até obter algum reconhecimento pelo mercado, a oferta de investimento é limitada.

Todavia, além do investimento financeiro é importante destacar outras formas de apoio não financeiro às startups, oriundos por exemplo de incubadoras e aceleradoras, lembrando que as últimas também podem oferecer apoio financeiro. Segundo Macedo (2015), as incubadoras de empresas são um dos agentes facilitadores do processo de geração de novos empreendimentos e propiciam inúmeras conexões que favorecem o crescimento do negócio e o acesso ao mercado. De acordo com a Associação de Parques Tecnológicos e Incubadoras de Empresas - Anprotec (2002), a incubadora pode ser definida sob três aspectos: a) promotora do desenvolvimento, geração e consolidação de micro e pequenas empresas (MPE); b) sistema que impulsiona a criação e o desenvolvimento de MPE por meio da formação complementar do empreendedor em seus aspectos técnicos e gerenciais; e c) facilitador do processo de empresariamento e inovação tecnológica para MPE. Neste sentido, é relevante ressaltar a importância que a incubadora tem no contexto de criação de novos empreendimentos de base tecnológica e na articulação entre instituições de pesquisa e o mercado, principalmente quanto beneficiadora e apoiadoras de programas de suporte a inovação e à difusão tecnológica (OCDE, 2005).

Raupp e Beuren (2009), argumentam que incubadoras procuram promover a redução de instabilidades. Os autores tratam da questão dos serviços e recursos ofertados pela incubadora a seus incubados, tendo como foco as dificuldades e facilidades das empresas incubadas nas diversas fases do processo de incubação. Como facilidades são citados: infraestrutura da incubadora, divulgação do produto, apoio da universidade, participação em eventos, redução de custos, oportunidades de negócios, acesso a pesquisadores e troca de experiências com outras empresas e consultorias. Sob o aspecto das dificuldades têm-se: falta de recursos financeiros e de conhecimento em gestão empresarial, comercialização do produto, regularização da empresa 
e sua inserção no mercado, lançamento de novos produtos, gastos com impostos, fidelização de clientes e assessoria técnica.

Em se tratando dos impactos gerados pelas incubadoras, Martins (2013), aponta que elas possuem um papel diferenciado para o empreendedorismo inovador, pois a incubação insere os empreendedores em importantes redes de negócios, que os auxiliam a desenvolver P\&D, angariar fomento e a participar de capacitações. Além disso, percebe-se também a importância das redes de clientes e fornecedores que se cria no ambiente de incubação, sendo uma oportunidade de negócio, além do apoio significativo das incubadoras nos serviços diários das empresas incubadas. O processo de incubação é mundialmente reconhecido como um dos mecanismos mais eficazes para lançar e desenvolver novos empreendimentos. No Brasil e no mundo as estatísticas revelam que a taxa de mortalidade de empresas que passam pelo processo de incubação é reduzida de $70 \%$ para $20 \%$ em comparação com as empresas iniciadas, normalmente, por conta e risco dos empreendedores (ARAÚJO et al, 2013).

Mais recentemente, observa-se o surgimento e desenvolvimento das aceleradoras de empresas, trazendo um novo tipo de organização para a economia. Segundo Abreu (2016), as aceleradoras procuram atrair e selecionar startups que tenham um enorme potencial de impacto para, ao longo de um programa de apoio bem estruturado, ajudá-las a criar valor e ganhar escala, e se desenvolver em um mercado competitivo. $\mathrm{O}$ autor ainda coloca que as aceleradoras ajudam os empreendedores a definir e construir os seus produtos iniciais, identificar segmentos de clientes, e obter recursos incluindo capital e funcionários. As aceleradoras são compostas por empreendedores experientes que provém serviços, espaços, conhecimentos na área de gestão, mentorias, rede de contatos e um forte conhecimento em criação de novos negócios para empresas nascentes, com o objetivo de ajudá-las a serem bem-sucedidas e se desenvolver em meio ao mercado competitivo (LYNN, 2012). Para alcançar o sucesso na aceleração de startups, cada aceleradora faz uma análise de desenvolvimento determinando assim os melhores métodos que irá utilizar. Eles representam os planos de trabalho a serem cumpridos dentro do tempo determinado para aceleração de cada novo empreendimento, para que assim possam atingir o melhor desenvolvimento (SARMENTO, 2016).

As incubadoras e aceleradoras apresentam uma grande similaridade, ambas têm o intuito de auxiliar os empreendedores no estágio inicial dos seus negócios. Porém na aceleradora os programas de apoio têm duração mais limitada que nas incubadoras e os recursos oferecidos são financeiros e de conhecimento, enquanto as incubadoras fornecem apenas recursos de conhecimento. Assim pode-se ressaltar como diferenças a duração distinta dos programas, percepções em relação aos recursos que cada um oferece e estágios em que uma se faz mais necessária do que a outra (COHEN, 2013).

Buscando ilustrar alguns estudos mais recentes a respeito das formas de apoio as startups, pode-se citar pesquisas como de Abreu (2016), Sarmento (2016), Nascimento (2015), Lima (2014), Moraes (2015), Raupp e Beuren (2009).

O estudo de Abreu (2016), buscou analisar o papel das aceleradoras de startups no Brasil por meio da análise de informações sobre o mercado, identificação de seu nível de contribuição para o ecossistema empreendedor brasileiro, além de ferramentas e informações do processo de aceleração que auxiliaram no desenvolvimento de novos negócios. Os resultados apontaram que as aceleradoras cumprem com o esperado, tendo influência direta no desenvolvimento de novos negócios por todo o país, apesar de ter uma concentração maior no Estado de São Paulo. 
O estudo de Sarmento (2016), parte de um objetivo semelhante de analisar o papel das aceleradoras na consolidação de novas empresas utilizando um método em que os próprios empreendedores saiam em busca de contatos ou desenvolvam essa captação via web. O estudo relata ainda como se dá o ciclo de aceleração e a relação que se dá entre as startups e a aceleradora observando as dificuldades desse processo e os benefícios desse relacionamento. Porém, nos casos em que o mercado é muito específico, a equipe da aceleradora intervém junto a eles, criando portais e expandindo a rede de relacionamento. Além disso, o processo de aceleração direciona e capacita as startups principalmente nas primeiras etapas do negócio, onde os riscos são consideravelmente maiores.

Nascimento (2015), em seu estudo busca compreender a influência do aporte de recursos oriundos de fundos de venture capital sobre atividades de inovação, a partir dos recursos e capacidades organizacionais. Com os resultados do estudo pode-se concluir que os principais recursos organizacionais como recursos financeiros, humanos, organizacionais e reputacionais, sofreram maior influência de aspectos que se relacionam ao desempenho gerencial, à alocação de recursos, à identificação de trajetórias e opções gerenciais tendo uma grande influência das atividades inovadoras. Ainda de acordo com os resultados as modificações empreendidas pelo fundo estão orientadas ao crescimento mercadológico das empresas aportadas, por meio do estabelecimento de planos estratégicos e mecanismos de monitoramento e controle.

O estudo de Lima (2014), buscou analisar as características do investimento em inovação e as peculiaridades crowdfunding que dificultam sua viabilização, além disso tentou evidenciar algumas das principais formas de investimento em inovações existente citando suas vantagens e desvantagens. A análise do estudo, mostrou que há espaço para inovações financeiras como o crowdfunding no mercado, pois existe uma fatia de empresas que não é atendido pelo mercado de crédito privado que demanda garantias reais para realizar empréstimos. Por outro lado, também não é atendido pelo mercado de capital de risco que está interessado em empresas mais desenvolvidas e cujo retorno, isto é, sua venda seja mais rápida. Por fim, Raupp e Beuren (2009), buscaram averiguar os programas que as incubadoras brasileiras disponibilizam às empresas incubadas. $\mathrm{O}$ resultado que se obteve com a pesquisa é positivo pois facilitam o processo de incubação, amenizando as dificuldades como desenvolvimento do produto ou serviço e a colocação dos mesmos no mercado.

\section{METODOLOGIA}

O presente estudo é classificado como uma pesquisa interpretativa qualitativa básica, de natureza descritiva. Segundo Godoy (1995), algumas características básicas identificam os estudos denominados "qualitativos". Segundo esta perspectiva, um fenômeno pode ser melhor compreendido no contexto em que ocorre e do qual é parte, devendo ser analisado numa perspectiva integrada buscando a hierarquização das ações de descrever; compreender, explicar, analisar a precisão das relações entre o global e o local em determinado fenômeno (GERHARDT; SILVEIRA 2009). Para tanto, o pesquisador vai a campo buscando "captar" o fenômeno em estudo a partir da perspectiva das pessoas nele envolvidas, considerando todos os pontos de vista relevantes.

Na pesquisa interpretativa qualitativa básica os dados podem ser coletados por meio de entrevistas, observação e análise documental (MERRIAM, 2009). Na presente pesquisa o instrumento de coleta de dados ser utilizado foi um roteiro de entrevista semiestruturado. As 
entrevistas foram feitas pessoalmente com três proprietários e três diretores de startups localizadas em Uberlândia - MG, realizadas entre os meses de julho a outubro de 2018. Após a coleta de informações em campo, os dados foram analisados por meio de análise de conteúdo das entrevistas, que segundo Silva e Fossá (2015), é uma técnica de análise das comunicações, que visa analisar o que foi dito nas entrevistas ou observado pelo pesquisador. Na análise do material, busca-se classificá-los em temas ou categorias que auxiliem na compreensão do que está por trás dos discursos. Para o desenvolvimento da análise de conteúdo, foram elaboradas categorias de estudo, por meio do referencial teórico, as quais são apresentadas no Quadro 1:

\section{Quadro 1: Categorias de análise}

\begin{tabular}{|c|c|l|}
\hline Autores & Categoria & \multicolumn{1}{|c|}{ Perguntas } \\
\hline $\begin{array}{c}\text { Ries (2012); } \\
\begin{array}{c}\text { Vasconcelos e } \\
\text { Wilkinson (2008); } \\
\text { Ferrão (2013) }\end{array}\end{array}$ & $\begin{array}{c}\text { Modelo de } \\
\text { negócio }\end{array}$ & $\begin{array}{l}\text { 1) Quais principais barreiras que você encontrou para colocar sua } \\
\text { ideia em prática? } \\
\text { 2) O que te motivou a criar sua própria startup? } \\
\text { 3) Por que você optou por esse modelo de negócio? }\end{array}$ \\
\hline $\begin{array}{c}\text { Dornelas (2008); Cohen } \\
\text { (2013); Abreu (2016); }\end{array}$ & $\begin{array}{c}\text { Apoio não } \\
\text { financeiro }\end{array}$ & $\begin{array}{l}\text { 4) Quais tipos de apoio (não financeiros) você obteve no início, } \\
\text { para começar a criação e desenvolvimento de sua empresa? } \\
\text { 5) Quais foram benefícios que você e sua empresa obtiveram } \\
\text { com esse apoio? }\end{array}$ \\
\hline $\begin{array}{c}\text { OCDE (2005); Lemes } \\
\text { Jr.; Rigo; Cherobim, } \\
\text { (2010); Nascimento }\end{array}$ & $\begin{array}{l}\text { Apoio } \\
\text { financeiro }\end{array}$ & $\begin{array}{l}\text { 6) Que tipos de financiamento/apoio financeiro você buscou para } \\
\text { o desenvolvimento da startup? } \\
\text { 7) Quais as dificuldades enfrentadas para conseguir } \\
\text { financiamento? } \\
\text { 8) Para alcançar o sucesso, você vê como necessário o aporte } \\
\text { financeiro de terceiros? Explique }\end{array}$ \\
\hline
\end{tabular}

Fonte: Autores

\section{RESULTADOS E DISCUSSÕES}

Para melhor identificação dos dados coletados, as empresas e os entrevistados estão caracterizados nos respectivos quadros abaixo (Quadro 2 e Quadro3). Nos próximos tópicos encontram-se os principais resultados da pesquisa divididos de acordo com as três categorias de análise: modelo de negócio, apoio não financeiro e apoio financeiro.

\subsection{Caracterização das empresas e entrevistados}

Quadro 2: Descrição das empresas analisadas

\begin{tabular}{|c|c|l|}
\hline Empresa & Ramo de atividade & \multicolumn{1}{c|}{ Histórico da empresa } \\
\hline Empresa E1 & SaaS / Fintech & $\begin{array}{l}\text { A empresa foi criada em novembro de 2016, a partir da ideia de três } \\
\text { sócios, em resolver problemas na prestação de contas de despesa de } \\
\text { reembolso. A empresa possui mais de 200 clientes em todo o Brasil, } \\
\text { conta com uma equipe de sete pessoas e já recebeu duas rodadas de } \\
\text { investimentos. }\end{array}$ \\
\hline Empresa E2 & $\begin{array}{l}\text { Marketplace de } \\
\text { alimentação }\end{array}$ & $\begin{array}{l}\text { A empresa foi criada em 2008, corresponde a um marketplace no setor } \\
\text { de alimentação, na qual permite com que restaurantes possam } \\
\text { cadastrar suas ofertas, somente efetivando o pagamento quando as } \\
\text { vendas são realizadas. }\end{array}$ \\
\hline
\end{tabular}




\begin{tabular}{|c|c|c|}
\hline Empresa E3 & $\begin{array}{l}\text { Tecnologia da } \\
\text { Informação - voltada } \\
\text { para RH }\end{array}$ & $\begin{array}{l}\text { Criada em 2017, a empresa detém foco em otimizar e automatizar os } \\
\text { processos de RH das organizações, visando modernizar seus processos } \\
\text { de gestão e estabelecendo uma relação eficiente entre as empresas e a } \\
\text { digitalização. Suas atividades foram iniciadas a partir da ideia de seus } \\
3 \text { sócios e conta com mais de } 150 \text { funcionários. }\end{array}$ \\
\hline Empresa E4 & $\begin{array}{l}\text { Tecnologia da } \\
\text { Informação - voltada } \\
\text { para a Logística }\end{array}$ & $\begin{array}{l}\text { A empresa foi fundada em } 2016 \text { com a ideia de } 3 \text { sócios, se refere a } \\
\text { um marketplace de fretes que buscam integrar a indústria e } \\
\text { distribuidores junto a transportadoras e motoristas autônomos na } \\
\text { plataforma. Conta com mais de } 180 \text { funcionários. }\end{array}$ \\
\hline Empresa E5 & $\begin{array}{l}\text { Tecnologia da } \\
\text { Informação }\end{array}$ & $\begin{array}{l}\text { Fundada em 2015, gerenciada pelo grupo de } 4 \text { sócios, a empresa é } \\
\text { especialista em engajamento e comunicação digital, pioneiros no } \\
\text { mercado de CRM Mobile no Brasil. Atualmente a empresa conta com } \\
\text { uma equipe de } 90 \text { funcionários. }\end{array}$ \\
\hline Empresa E6 & Financeiro/Jurídico & $\begin{array}{l}\text { A empresa foi fundada em 2016, partindo da ideia de dois sócios em } \\
\text { fazer um mercado digital para a negociação de precatórios no Startup } \\
\text { Weekend BH. Participou do programa de pré-aceleração Lemonade, } \\
\text { Darwin Startups, FIEMG Lab. Recebeu duas rodadas de } \\
\text { investimentos. A empresa conta com uma equipe de } 10 \text { pessoas, oito } \\
\text { clientes. }\end{array}$ \\
\hline
\end{tabular}

Fonte: Autores

Quadro 3: Descrição dos entrevistados

\begin{tabular}{|c|c|c|l|l|}
\hline Empresa & Entrevistado & Idade & \multicolumn{1}{|c|}{ Escolaridade } & \multicolumn{1}{|c|}{ Função } \\
\hline E1 & P1 & 29 & Mestrado completo & CEO \\
\hline E2 & P2 & 31 & Superior completo & Comercial/CEO \\
\hline E3 & P3 & 33 & Mestrado completo & $\begin{array}{l}\text { Estratégia, Negócios, Marketing, Financeiro, } \\
\text { Recursos Humanos }\end{array}$ \\
\hline E4 & P4 & 32 & Ensino médio completo & CEO \\
\hline E5 & P5 & 29 & Superior completo & Diretor de operações \\
\hline E6 & P6 & 30 & Mestrado Completo & Diretor de operações \\
\hline
\end{tabular}

Fonte: Autor

\subsection{Descrição do modelo de negócio}

Quanto a motivação dos profissionais em montar sua startup, as principais justificativas foram associadas a busca em atender um problema já observado na sociedade, além da expectativa em deixar a estagnação do mercado de trabalho e empreender.

P1: “(...) o que motivou sair do mercado tradicional e montar minha empresa foi muito a questão da estagnação, então, eu estava me sentindo estranho, nada ali no emprego que eu tava. Não em questão de salário, né. Foi mais questão de conhecimento".

P2: "O principal motivo foi a oportunidade de resolver um grande problema. $\mathrm{O}$ desperdício de alimentos é algo que impacta o mundo. Ele gera aumento nos preços dos alimentos e lixo para o meio ambiente".

A habilidade de identificar novas oportunidade de mercado é uma das principais características dos empreendedores. Autores como Vasconcelos e Wilkison (2008), destacam o empreendedor como um agente capaz de explorar novas oportunidades, que não tenha medo de atuar com inovações, sendo essa uma relevante forma de contribuir com o crescimento de uma organização.

P5: “(...) eu sentia um problema diariamente da parte de relacionamento com os clientes, principalmente na parte dos aplicativos móveis. Daí eu tive uma noção bem 
interessante de como arrumar isso. Eu já sabia que tinha um jeito de fazer isso bem

feito e tudo mais, e que tinha poucas pessoas fazendo isso".

No que tange a escolha sobre o modelo de negócio adotado, a maioria dos entrevistados citou a capacidade de trabalhar com escala, atividades em massa e o tamanho do mercado, como as principais justificativas para a adoção do modelo adotado em suas startups.

P1: “(...) era buscar a escala, foi o principal motivo que a gente deixou de ser só o modelo sobre demanda negócio recorrente para poder vender para o Brasil inteiro.

P2: "Esse modelo ajuda a ganhar escala de forma mais rápida".

P4: "Primeiro pelo tamanho do mercado, o mercado muito grande, movimenta muito dinheiro e os principais pontos que você tem que analisar, quando você quer um negócio, é qual o tamanho desse mercado".

Respectivas considerações corroboram aos apontamentos de Ries (2012), que apresenta as startups como empresas que nasceram a partir de uma ideia inovadora, com predominância em adotar modelos de negócio escalável, repetível, mas inserido em um ambiente de incerteza no cenário organizacional. Apenas um dos entrevistados citou o conhecimento que já tinha, como um motivo de escolha para o modelo de negócio adotado na sua empresa.

P5: “ (...) o modelo de negócio que a gente escolheu, que é trabalhar nesse negócio, foi porque a gente conhecia muito, a gente conhecia os problemas, sabíamos muito sobre aplicativos móveis, sabíamos que conseguiríamos melhorar a performance deles e sabíamos que o modelo startup era um modelo voltado a tecnologia e que aceitava bem nossa ideia e de sabermos onde queríamos chegar e do nosso potencial".

De acordo com entrevistado, a justificativa também é apresentada por Ferrão (2013), que destaca a importância do know how dos profissionais envolvidos na fundação das startups, sendo os conhecimentos e as experiências vividas no mundo empresarial como um fator relevante ao crescimento acelerado que esse tipo de organização pode obter.

A partir das entrevistas realizadas, foi possível verificar que as principais barreiras encontradas para colocar a ideia de negócio em prática estão de acordo com os achados de Sarmento (2016), estão associados a falta de recursos humanos, de conhecimento do mercado e recursos financeiros. Conforme Ferrão (2013), o know how dos profissionais envolvidos no desenvolvimento de uma startup é fonte fundamental para garantir o seu sucesso no mundo empresarial. Essa falta de recursos foi apontada pelos entrevistados, que justificam como uma barreira para o desenvolvimento de suas ideias de negócios. Autores como Sarmento (2016) e Raupp e Beren (2009), apresentam a falta de obtenção de recursos para financiar os projetos, como dificuldade iniciais dos empreendedores nesse modelo de empresa. Já Ries (2012), justificam a incerteza do cenário desse modelo de empresa como um critério e barreira para o desenvolvimento de fontes de financiamento para suas atividades.

P3: “(...) é muito difícil a você a juntar as competências necessárias para colocar uma ideia em prática".

P4: “As principais barreiras que eu encontrei (...) você quer executar essa ideia, você precisa então é ter uma receita para poder investir nessa ideia e fazer ela virar, tirar do papel e fazer acontecer".

P6: "(...) a falta de conhecimento do mercado e falta de maturidade do modelo de negócio são aspectos que nos restringe muito, razão pela qual foi necessário o pivot da ideia original".

\subsection{Apoio não financeiro}

O apoio não financeiro na criação de um startup é de extrema relevância para o seu sucesso no mercado. Dentre esse tipo de apoio, as principais considerações dos entrevistados 
apontam os familiares, a rede de contatos e mentorias como os principais recursos utilizados pelos empreendedores.

P1: “(...) o primeiro é família e o segundo é o conhecido networking que se faz ao longo da carreira, foi o que possibilitou a gente passar pelas barreiras".

P2: "No momento de validação do negócio é importante ter mentores ou pelo menos falar com pessoas mais experientes na área. Esse conhecimento evita a você cometer erros e gastar tempo e dinheiro de forma desnecessária".

P3: "no início obtivemos o apoio pré-aceleração onde pudemos realizar o planejamento estratégico do nosso empreendimento, analisando o mercado, desenvolvendo o modelo de negócios, criando o MVP (produto mínimo viável), levantando as informações financeiras e estabelecendo as metas e nossas estratégias de vendas com base nas informações e feedback (...) pra mim apoio é o networking. Acho que sem ele não teríamos o sucesso esperado. A pré aceleração nos ajudou na criação desse networking, você ter contatos de pessoas que tem o conhecimento necessário na área e estão dispostas a ajudar é essencial para o sucesso.

De acordo com Abreu (2016), a participação das aceleradoras e dos programas de mentorias existentes são relevantes ao contribuir para o desenvolvimento dos empreendedores, no qual seus papéis são cumpridos, influenciando diretamente no desenvolvimento de novos negócios em todo o Brasil. Além disso, o apoio das redes de networking auxilia na disseminação de experiências, nas quais podem auxiliar no desenvolvimento das atividades, visando a redução de erros nas tomadas de decisões.

Somente um dos entrevistados não citou os programas de aceleração ou incubadoras, como relevante fonte de apoio na criação da sua startup, destacando apenas a importância de networking no mundo empresarial e os conhecimentos já obtidos com as experiências no mercado.

P5: Antes de começar a empresa trabalhei muito tempo, e as habilidade adquiridas de ambos os sócios da empresa ajudaram, trabalhei muito tempo na área de inovação, mobile (...) etc. /// acho que nesse momento toda parte de planejamento tudo mais que a gente consegui fazer através da metodologia de consultoria que eu fazia na época com uma equipe de pessoas me ajudou muito na época a alavancar isso. $\mathrm{O}$ apoio de pessoas também e essencial sempre buscando pessoas que pudessem nos guiar a favor de nossos objetivos foi outro aspecto essencial.

Quanto aos benefícios obtidos com o apoio não financeiro, acima citados, os entrevistados destacaram os conhecimentos obtidos, no qual se refletiram no crescimento e sucesso dessas organizações.

P2: "Foram muito importantes. Além do fator racional de falar com os mentores para aprender, é sempre bom para te motivar a seguir em frente. Porque a jornada de criar algo novo geralmente é bem desgastante e você sempre deve estar muito motivado para seguir em frente e motivar seus parceiros".

P4: “ (...) eu cresci muito mais rápido do que o que cresceria se eu não tivesse esses caras então com ajuda deles eu obtive conhecimento e crescimento então foi o apoio fundamental para o meu negócio desenvolver".

As considerações apresentadas pelos entrevistados corroboram ao exposto por Sarmento (2016), o qual relata que as mentorias são relevantes ao intervir em fases iniciais das startups, visando contribuir com a eficiência dos negócios e a redução dos riscos, que nesse estágio inicial são consideravelmente maiores. O entrevistado P1 destacou que todo os apoios não financeiros obtidos, refletiram nos seus resultados financeiros, auxiliando no crescimento da empresa. P1: " Ajudou a superar barreiras em colocar isso no mercado e a faturar mais". 
Pode-se concluir que o apoio não financeiro é importante para diminuir a taxa de mortalidade das empresas, seja por meio de incubadoras (ARAÚJO et al, 2013; MARTINS,2013) ou aceleradoras (COHEN, 2013) até mesmo pela rede de relacionamento que uma comunidade de startups e ecossistema de inovação podem proporcionar .

\subsection{Apoio financeiro}

A principal motivação do presente estudo envolve as formas de apoio financeiro que as startups adotam em seus estágios de fundação. Conforme apresentado pelo Manual de Oslo (OCDE, 2005), existem diversos mecanismos de financiamento para as atividades de inovação, incluindo os recursos próprios dos sócios, corroborando ao apontado pelos entrevistados. Os resultados apontam que alguns profissionais não fizeram uso de programas de investimentos como forma de financiamento, obtendo o apoio apenas de recursos próprios ou de sócios.

P2: "Até o momento foi somente financiamento do próprio bolso, também conhecido no meio de startup como bootstrap. A decisão foi crescer o máximo a empresa com recursos próprios e só depois pensar em abrir para investidores quando a empresa já estiver mais valorizada".

P4: "Meu caso, eu tinha um sócio que já estava buscando algo, um modelo que ele já tinha desenvolvido. Daí ele me deu oportunidade entrar já em uma grande empresa debaixo desse produto".

Além disso, o Manual de Oslo também destaca o uso de outras fontes de captação de recursos, seja de outras empresas subsidiárias ou associadas, empréstimos bancários, programas de aceleração ou financiamento pelo governo. Isso é apresentado por quatro dos profissionais entrevistados, nos quais apontaram utilizar de programas de programas de aceleração como fonte de financiamento para o desenvolvimento das atividades de suas respectivas startups, investindo os recursos nas áreas de marketing, pessoas e produção.

P1: “ (...) como a gente já tinha aquela primeira empresa ela já faturava, então meio que financiou essa segunda ideia nessa startup (...) uma vez que sabíamos que a gente ia precisar de mais grana e mais conhecimento a gente foi para aceleradora (...) então a gente foi pra essa que é uma das melhores aceleradora da América Latina (...) com os recursos investimos muito em marketing e em produção".

P3: "O financiamento a gente buscou logo no início, o programa Pipe da Fapesp que apoia com R\$200.000,00 em recursos não reembolsáveis, basicamente para contratação de pessoas, bolsistas para ajudar no desenvolvimento de uma ideia".

P5: " Primeiramente a gente buscou um apoio de uma aceleradora, que além de apoio financeiro eles dão apoio de mentorias e consultorias, no começo a gente não pensava em buscar apoio de investidores por que era uma ideia muito nova, uma ideia ainda não tão madura, então a gente preferiu fazer o máximo com nossos "pés" (...)

P6: "Buscamos investimento através de programas de aceleração ou smart Money a expressão serve para descrever os investidores que além de aportar capital também serão um diferencial importante para a startup, pois ao mesmo tempo que conseguíamos expandir o time conseguíamos contato com o mercado e mentorias valiosas para estruturação do negócio, sobre como investir em marketing para vender melhor nossa ideia".

No que tange as dificuldades para obtenção das fontes de recursos financeiros, os entrevistados relataram questões referentes a deixar a família para prosseguir com os programas de aceleração em outras cidades, o equilíbrio de ideias junto as equipes, além da disposição em atender a todas as exigências nas quais eram solicitadas pelos investidores, visando reconhecer quem realmente era o melhor investidor a ser escolhido. 
P1: “As dificuldades enfrentadas foram que eu sou de Uberlândia né, então eu já estava casado, já tinha criado raiz aqui. Nunca tinha morado fora e para isso eu tive que, expandir minha cabeça, ir São Paulo em uma aceleradora. No começo, nos primeiros meses não teve apoio financeiro, então tive que tirar do meu próprio bolso para poder bancar".

P6: "Para a captação do investimento, como foi via aceleradoras, não houve muitas dificuldades de efetivo acesso ao dinheiro. Já na segunda rodada de investimento percebemos que há alguns investidores que não estão maduros o suficiente e exigem algumas demandas que não conseguimos entregar. Então saber aceitar o investimento correto e analisar o tipo de investidor que está fazendo a oferta é importantíssimo (...) entender e saber compreender o melhor investimento que atenda ambas as partes, é essencial.

Essas informações corroboram com o apontado pelo Manual de Oslo (OCDE, 2005), ao destacar que os programas de aceleração por vezes podem exigir muito do empreendedor, mas esse se faz necessário, pois busca de fato desenvolver as empresas com foco na inovação e à difusão tecnológica.

Já os profissionais que não participaram nos programas de aceleração, destacaram principalmente as economias necessárias para financiar as atividades da empresa, além das dificuldades em expor as ideias aos sócios, visando captar maiores recursos para investimentos nas atividades iniciais de marketing, produção e no aprimoramento da sua ideia de negócio.

P2: “Como não tivemos até o momento financiamento externo, a maior dificuldade foi tentar reduzir ao máximo as despesas pessoais e investir as reservas financeiras na empresa para a produção, marketing, recursos humanos".

P4: No meu caso eu não tive financiamento, tive sócios que acreditaram no projeto e colocaram um dinheiro para que ele pudesse ser desenvolvido. Mas as dificuldades são... é questão que o empreendedor brasileiro ainda tem muita dificuldade e de expor a ideia, de expor aonde ele vai qual, qual é o foco dele, pois no início acaba que tem essa dificuldade, pois os recursos assim que vão entrando, é que vai se investindo em marketing".

Esses resultados se assemelham aos estudos apresentados por Nascimento (2015), que destaca a necessidade dos empreendedores em analisar qual a melhor forma de obtenção de financiamento para as atividades de inovação de uma empresa. Ou seja, cabe ao empreendedor analisar o cenário, equilibrar os riscos e tomar as decisões mais assertivas nas escolhas de investimentos, considerando as dificuldades que possam vir a se apresentar durante essa respectiva trajetória.

Referente ao questionamento feito aos entrevistados sobre a associação do sucesso de uma empresa com a utilização de recursos financeiros de terceiro, é válido destacar que a maioria dos profissionais relataram concordar com essa relação de sucesso e apoio financeiro de terceiros.

P3: "Acho que é muito necessário aporte financeiro de terceiros para ter sucesso, porque no começo fica muito difícil alguns clientes te abrirem as portas".

P4: “(...) você precisa mapear isso, analisar isso, testar. Quando o produto tiver testado e você tiver uma base de clientes já funcionando aí você tem condição de chegar para outros investidores falar assim "cara eu preciso de grana para isso para poder escalar, para poder crescer para poder vender" essa é uma necessidade para o sucesso".

Apenas um dos entrevistados alegou não concordar com a relação do sucesso com o aporte financeiro de empresas terceiras, sendo justificado que depende do modelo de negócio do empreendedor, no qual alguns conseguem obter uma receita com as próprias vendas, sem a necessidade de capital e outros não. 
P2: Não acredito que seja necessário aporte financeiro de terceiros para a empresa virar sucesso. Existem casos de empresas que cresceram muito bem sem necessidade de capital externo, através da receita gerada dos seus clientes. Mas também existem modelos de negócios que precisam de capital para crescer, pois geram muita queima de caixa no início da operação. É possível ter sucesso atuando das duas formas.

As respectivas considerações apresentadas vão de acordo ao apontado por Lemes JR, Rigo e Cherobim (2010), no qual destacam que as diversas fontes de financiamento existentes pelo mercado auxiliam na estruturação de capital de outras empresas, todavia cabe ao empreendedor analisar se é necessário fazer uso desses recursos ou se o modelo de negócio adotado não exige esse tipo de recurso para se desenvolver em meio ao cenário empresarial.

\section{CONSIDERAÇÕES FINAIS}

O presente estudo buscou analisar como os empreendedores obtêm recursos para a criação de suas startups e de que forma tais recursos são aplicados. Atualmente, nota-se que as fontes de recursos, sejam elas financeiras ou não, são alternativas cada vez mais almejadas pelos profissionais que buscam a criação de suas startups.

Especificamente quanto a utilização das fontes de apoio financeiro, percebe-se que a principal alternativa citada pelos entrevistados se refere aos programas de aceleração. Os programas ofertam vários benefícios, mas também exigem muita dedicação e foco no cumprimento dos requisitos necessários para o ganho do investimento financeiro. Todavia, antes de aceitar o apoio financeiro é importante avaliar o perfil do investidor e as expectativas destes. Além destes programas, recursos próprios foram citados reforçando a premissa que cabe ao empreendedor analisar a peculiaridade do seu modelo de negócio e estipular o momento exato de investimentos externo. Quanto a aplicabilidade dos recursos financeiros, seja próprios ou seja de programas de aceleração, foi utilizada na contratação de pessoal, investimentos em marketing e na produção direta dos produtos e serviços a serem comercializados. Mais que o recurso financeiro, a pesquisa aponta que o apoio não financeiro, na forma de mentorias, rede de relacionamento, apoio de familiares, amigos, comunidades de apoio e outras conexões promovem um aprendizado que acelera e torna mais efetivo o desenvolvimento da ideia e estruturação do negócio inovador.

Cabe ressaltar que, para a execução desta pesquisa, houve dificuldades no reconhecimento dos empreendimentos quanto a classificação como startups. Demais organizações de base tecnológica abordadas para coleta de dados não possuíam as particularidades que caracterizam o modelo de negócio startup, por isso foram excluídas da análise. Como pesquisa futura sugere-se analisar o apoio de demais fontes de financiamento não citadas nas entrevistas, como crowdfunding, financiamento pelos bancos públicos e privados, e como estas fontes de financiamento promovem o desenvolvimento das startups.

\section{REFERÊNCIAS}

ABREU, P. R. M. O panorama das aceleradoras de startups no Brasil. Centro de Estudos em Private Equity e Venture Capital - GVcepe, 2016.

ABSTARTUPS. Saiba qual é o melhor tipo de investidor para sua startup. 2016. Disponível em: <https://abstartups.com.br/qual-o-melhor-investidor-para-startup>. Acesso em: 06 nov. 2018 
ARAÚJO, A. P.D. Análise da regulação do investimento anjo no Brasil. 2017.55f.

Monografia - Universidade Federal de Brasília - UNB, Brasília, 2017.

ARAÚJO, V. R. B. S. et. al. Avaliação de Empresas: um estudo em uma empresa incubada no Estado de Alagoas. In: 30ª Conferência Mundial IASP de Parques Científicos e Tecnológicos e XXIII Seminário Nacional de Parques Tecnológicos e Incubadoras de Empresas, APROTEC, Recife, 2013

ARRUDA, C.; NOGUEIRA V. Causas da mortalidade de startup brasileiras. O que fazer para aumentar as chances de sobrevivência no mercado. 2012.

ANPROTEC - ASSOCIAÇÃO NACIONAL DE ENTIDADES PROMOTORAS DE EMPREENDIMENTOS INOVADORES; SERVIÇO BRASILEIRO DE APOIO ÀS MICRO E PEQUENAS EMPRESAS. Planejamento e NOBRE ET AL (2016) HOLOS, Ano 32, Vol. 3. Brasília: Anprotec/Sebrae, 2002.

ATKINSON, R. D.; EZELL, S. J. Innovation economics: the race for global advantage. New Haven: Yale University Press, 2012.

CHEROBIM, A. P M. S.; MENDONÇA, A. T. B. B.; WOEHL, S.; NASCIMENTO, T. C. Capital de risco do Brasil: a atuação do fundo de capital semente CRIATEC. Revista Análise, Porto Alegre, v.22, n.2, p.189-201, 2011.

COHEN, S. What do accelerators do? Insights from incubators and ngels. Innovations: Technology, Governance, Globalization, v. 8, n. 3-4, p. 19-25, 2013.

DORNELAS, J. C. A. Planejando incubadoras de empresas. Rio de janeiro: Campus, 2008. FERRÃO, S. Empreendedorismo e empresas startup: uma nova visão estratégica como motor de empregabilidade jovem. Boletim de Sociologia Militar, p. 9, 2013.

GERHARDT, T.E.; SILVEIRA, D. T. Métodos de pesquisa. Porto Alegre: Editora da UFRGS, 2009.

GODOY, A. S. Pesquisa qualitativa: tipos fundamentais. Revista de Administração de empresas, v. 35, n. 3, p. 20-29, 1995.

HALL, B. H.; LERNER, J. The financing of R\&D and innovation. In: Handbook of the Economics of Innovation. North-Holland, 2010. p. 609-639.

HERMANSON, B. O que é uma startup? MUNDO SEBRAE, 2011. Disponível em: <http://www.mundosebrae.com.br/2011/01/o-que-e-uma-startup/>. Acessado em: 06 nov. 2018.

LEMES JR. A. B.; RIGO, C. M.; CHEROBIM, A. P. M. S. Administração financeira: princípios, fundamentos e práticas brasileiras. 3.ed. Rio de Janeiro: Elsevier, 2010.

LIMA, F. Q. Crowdfunding: renovando o financiamento à inovação. 2014. 57f. Monografia Universidade Federal de Brasília - UNB, Brasília, 2014.

LUNA, F.; MOREIRA, S.; GONÇALVES, A. Financiamento à inovação. Políticas de incentivo à inovação tecnológica no Brasil. IPEA: Brasília, p. 229-262, 2008.

LYNN, H. D. Analysis of accelerator companies: An exploratory case study of their programs, processes, and early results. Small Business Institute Journal, v. 8, n. 2, p. 54-70, 2012. 
MACEDO, L. S. A incubadora de empresas da universidade federal de Uberlândia: agente de inovação e desenvolvimento local. Cadernos de Prospecção, v. 8, n. 2, p. 203, 2015.

MARINHO, L. E. M. C. Startups: a mitigação dos riscos nos investimentos em startups de base tecnológica. 2017.63 f. Monografia - INSPER, São Paulo, 2017.

MARTINS, C. O papel das incubadoras de empresas do polo tecnológico de Florianópolis no desenvolvimento do processo de empreendedorismo inovador. 2013.269

f. Dissertação (Mestrado em Administração) - Universidade do Sul de Santa Catarina, Florianópolis, 2013.

MERRIAM, S. Qualitative reserch: a guide to design and impementation.San Francisco: Jossey-Bass. John Wiley \& Sons, 2009.

MORAES, R. R. Empreendedorismo startup e inovação em empresas incubadas de base tecnológica na região metropolitana de Belém. Revista de Administração e Contabilidade, v. 1, n. 2, 2015.

MORAES, R.R. Empreendedorismo startup: um estudo de caso em uma empresa de tecnologia no estado do Pará. Simpósio de Excelência em Gestão e tecnologia, 2012

NASCIMENTO, T C. Venture capital como instrumento de financiamento à inovação: implicações do aporte em startups brasileiras capitalizadas pelo Fundo CRIATEC. 2015.308f. Tese de Doutorado - UNIVERSIDADE FEDERAL DO PARANÁ, Curitiba, 2015.

OCDE. Organização para Cooperação e Desenvolvimento Econômico. Manual de Oslo: diretrizes para coleta e interpretação de dados sobre inovação. $3^{\mathrm{a}}$ ed. 2005.

RAUPP, F. M.; BEUREN, I. M. Programas oferecidos pelas incubadoras brasileiras às empresas incubadas. Revista de Administração e Inovação, São Paulo, v. 6, n. 1, p. 83-107, 2009.

RIES, E. A Startup Enxuta: como os empreendedores atuais utilizam a inovação contínua para criar empresas extremamente bem-sucedidas. São Paulo: Lua de Papel, 2012.

SARMENTO, M. R. C. O papel das aceleradoras na consolidação de novas empresas de cultura empreendedora a luz da metodologia Lean startup. EmpíricaBR - Revista Brasileira de Gestão, Negócio e Tecnologia da Informação, Natal, v. 1, n. 1, p. 65-86, 2016.

SCHUMPETER, J. A. Teoria do desenvolvimento econômico. São Paulo, Ed. Nova Cultural, 1985.

SILVA, A. H.; FOSSÁ, M.I.T. Análise de conteúdo: exemplo de aplicação da técnica para análise de dados qualitativos. Qu@alitas Revista Eletrônica, Campo Grande, v. 17, n. 1, p. 114. 2015. Disponível em:<

http://revista.uepb.edu.br/index.php/qualitas/article/view/2113/1403>. Acesso em 15 out. 2018.

VASCONCELOS, V. G.; WILKINSON. Empreendedorismo, inovação e redes: uma nova abordagem. Revista de Administração Eletrônica, São Paulo, v. 7, n. 1, jan/jun. 2008.

Disponível em: < http://www.scielo.br/pdf/raeel/v7n1/a08v7n1.pdf>. Acesso em 14 abr. 2019. UBERHUB. Disponível em: http://uberhub.com.br/. Acesso em 17 mai. 2019. 